\title{
Joining Titanium by Means of Ceramic Adhesives
}

Fabio Scherilloa, Andrea el Hassanin, Alessia Teresa Silvestri, Barbara Liguori, Paolo Aprea, Daniela di Martino and Vincenzo Contaldi

Fabio Scherilloa. University of Naples 'Federico II', Department of Chemical, Materials and Industrial Production Engineering, Italy

Corresponding author: fabio.scherillo@unina.it

Andrea el Hassanin. University of Naples 'Federico II', Department of Chemical, Materials and Industrial Production Engineering, Italy

Alessia Teresa Silvestri. University of Naples 'Federico II', Department of Chemical, Materials and Industrial Production Engineering, Italy

Barbara Liguori. University of Naples 'Federico II', Department of Chemical, Materials and Industrial Production Engineering, Italy Paolo Aprea. University of Naples 'Federico II', Department of Chemical, Materials and Industrial Production Engineering, Italy Daniela di Martino. MBDA Italia S.p.A., Italy

Vincenzo Contaldi. MBDA Italia S.p.A., Italy

Abstract. Ceramic adhesives are an interesting alternative to traditional methods to join metal to ceramics such as fastening, vacuum brazing and gluing. Ceramic adhesives are made of an inorganic matrix with a filler (alumina, zirconia, silica, etc.), and they require a thermal cure cycle in order to establish adhesion. In this work, the adhesion between two different adhesive and Ti6Al4V is studied in details and the influence of the curing cycle is analyzed. Two different adhesives have been used, the first made of a phosphate matrix with an alumina filler, the second made of a silicate matrix wit an alumina filler. The results indicates that in the case of the first adhesive a high temperature cure it is necessary in order to establish a strong adhesion with the metal; on the contrary the second adhesive is capable to create a strong bonding already at low temperature.

Keywords. Ceramic Adhesives, Ti6Al4V, Adhesion Strength

\section{Introduction}

The realization of mixed structures such as ceramic-metals is a mayor goal of industry. These types of structures find application in biomedical, aerospace mechanical, civil and other important engineering sectors $[1,2]$.

A ceramic to metal joint is difficult to realize for different reasons; firstly, metal and ceramic usually have a very different thermal expansion coefficient, with the consequence of high interface stresses if the joint is subjected to thermal excursion.

Secondly, metals and ceramics are poorly compatible from a chemical point of view, due to their intrinsically different nature, meaning that strong bonding is difficult to establish.

Different technologies are available to realize a metal to ceramic joint, such as mechanical fastening, brazing and gluing. Brittleness is the major obstacle to creating a fastened joint, in fact fastening usually requires preliminary works like drilling and those operations are very difficult on ceramic materials [3].

Active brazing is at present the most widespread technology to create a metal-ceramic joint. However, in order to ensure an adequate adhesion strength, the ceramic surface must be prepared through complex operation, like multiple metal plating.

An alternative to active brazing is reactive brazing, where a conversion layer is established between the filler material 
and the ceramic surface. In this case, metal coating is unnecessary, but not all types of ceramics are suitable to be processed in this way [4].

Brazing of ceramics is always conducted under vacuum furnaces, and requires specialized work.

Gluing is a technology where the adhesion between two different surfaces is realized by means of the interposition of an adhesive, typical and widely used adhesives are polymer based [5].

These types of adhesives usually guarantee a strong adhesion, but their principal limit is durability, in fact the joints must be reprocessed after a period of time.

Ceramic adhesives are made of an inorganic matrix with a filler (alumina, zirconia, silica, etc.). They require a thermal cure cycle in order to establish adhesion, but the process operations are easier with respect to brazing. Their main advantage is environmental resistance.

In this work two commercial ceramic adhesives are tested with an Ti6Al4V alloy. This alloy is often used to realize metal- ceramic joints due to its low thermal expansion coefficient. Moreover, Ti is a very reactive metal that easily forms conversion layer with inorganic substances that improve adhesion strength between surfaces. The adhesion strength has been evaluated by means of tensile test conducted on metal-metal lap joint.

\section{Materials and methods}

Two different ceramic adhesives have been used in this work, the first, Aremco 503, is made of a phosphate matrix with an alumina filler, the second, Aremco 552, is made of a silicate matrix with an alumina filler.

The standard cure cycles, suggested by the producer, are reported in the following:

For 503 adhesive: exsiccation at room temperature for 2 hours, holding at $96^{\circ} \mathrm{C}$ for 2 hours, holding at $260{ }^{\circ} \mathrm{C}$ for 2 hours, holding at $370{ }^{\circ} \mathrm{C}$ for 2 hours then furnace cooling.

For 552 adhesive: exsiccation at room temperature for 2 hours, holding at $96^{\circ} \mathrm{C}$ for 2 hours, holding at $260{ }^{\circ} \mathrm{C}$ for 2 hours, then furnace cooling.

The adhesive strength between the adhesives and the Ti6Al4V alloy has been tested by tensile test, to this aim lap joint with overlapping area of $25 \times 25 \mathrm{~mm}$ have been realized using a titanium sheet of $1 \mathrm{~mm}$ thickness.

The tensile tests have been conducted using a Galdabini machine imposing a velocity of $0.3 \mathrm{~cm} / \mathrm{s}$ between the jaws.

In order to evaluate the influence of temperature on adhesion strength some samples have been cured at $700{ }^{\circ} \mathrm{C}$ for 2 hours after the standard cure cycles reported above.

The effect of the curing temperature on the interaction between metal and ceramic adhesive has been studied analyzing the bonding interface by means of Scanning Electron Microscope Hitachi TM 3000 coupled with an Oxford Instrument Swift ED3000 EPDMA probe. To this aim the composition profiles of the main elements of metal alloy and ceramic adhesives have been measured.

Other information on the adhesion has been deduced analyzing the fracture surfaces.

\section{Results and discussion}

The modification occurring during the cure of ceramic adhesives like those employed in this work are described in 
literature [6,7].

At the end of the curing cycle, the 503 adhesive is made of a matrix of partially amorphous structure of aluminum phosphate with the alumina filler dispersed inside. The 552 adhesive is essentially constituted of an amorphous geopolymer of aluminosilicates with the alumina filler dispersed inside.

The morphology of fracture surface is reported in figure 1. It can be noticed that the fracture, independently from the curing cycle, is mixed for both the adhesives and the failure occurs partially at the interface between metal and ceramic.

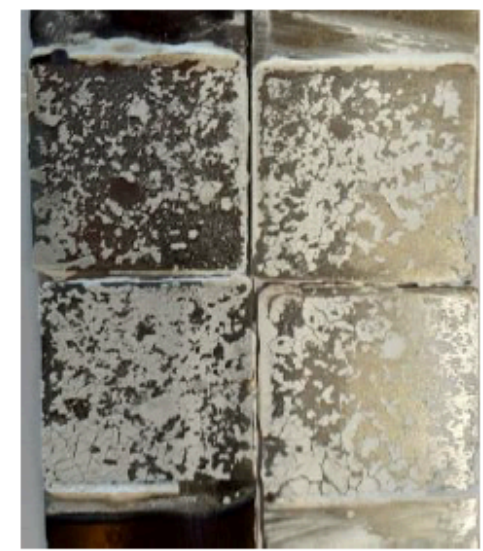

$\boldsymbol{a}$

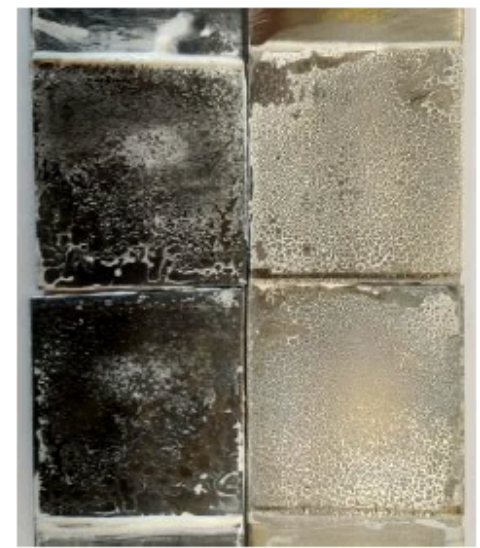

$b$

Fig. 1. Morphology of fracture surface in the case of 503 adhesive (a) and 552 adhesive (b). Standard curing Cycle.

The results of tensile tests (see figure 2) indicate that, relatively to the 503 adhesive, the further curing step at $700{ }^{\circ} \mathrm{C}$ has improved the adhesion strength.

On the contrary, in the case of 552 adhesive, there is no evidence of an effect of the cure temperature on adhesion strength.
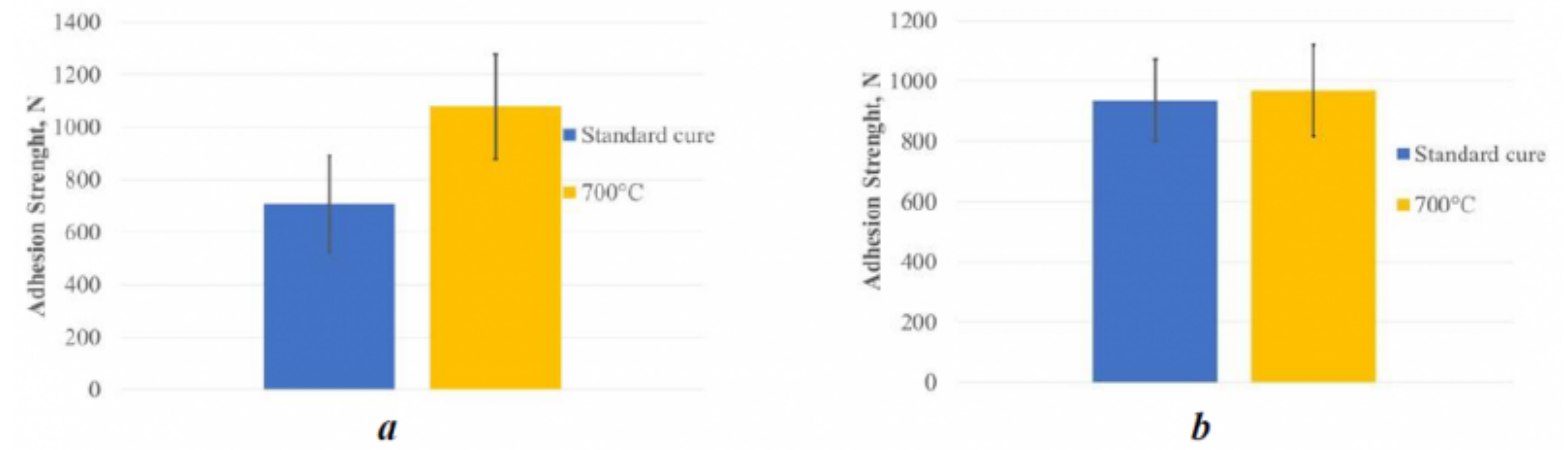

Fig. 2. Results of tensile test showing the influence of temperature on the adhesion strength. (a) 503 adhesive; (b) 552 adhesive. 
The explanation of this behavior is given by the analysis of the interface, particularly by the composition profiles reported in figures 3 and 4 .

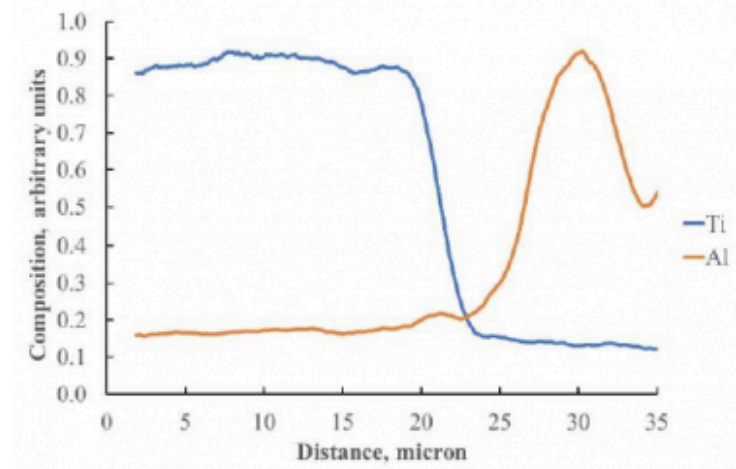

a

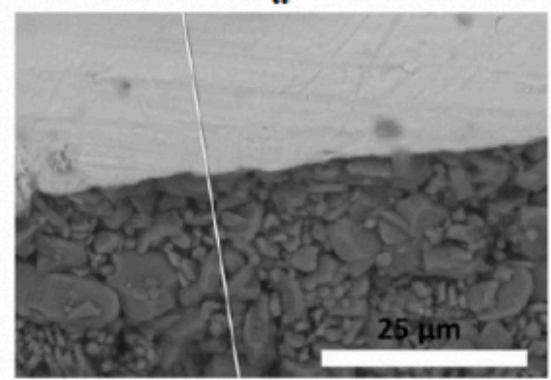

$c$

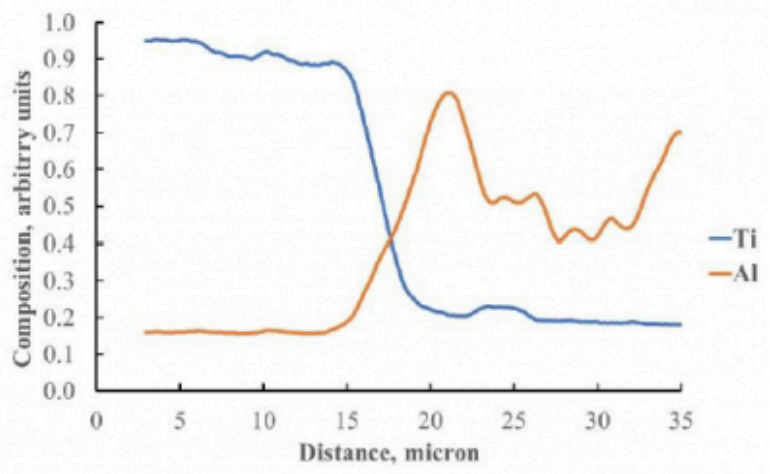

b

Fig. 3. Composition profiles of $\mathrm{Ti}$ and $\mathrm{Al}$ across the interface metal-ceramic (c); 503 adhesive after standard curing cycle (a) and after $700{ }^{\circ} \mathrm{C}$ curing step (b).

In the case of 503 adhesive and standard cure cycle, there is not interdiffusion between the metal alloy and the ceramic, in fact the curve relative to titanium drops in correspondence of the interface without penetration inside the ceramic, and symmetrically $\mathrm{Al}$ does not penetrate inside the metal. At $700{ }^{\circ} \mathrm{C}$, on the contrary, the composition profiles of Ti and $\mathrm{Al}$ indicate that interdiffusion occurs. 


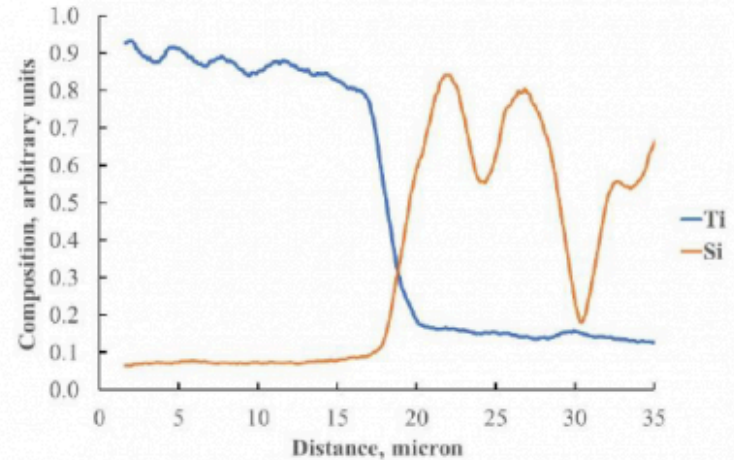

a

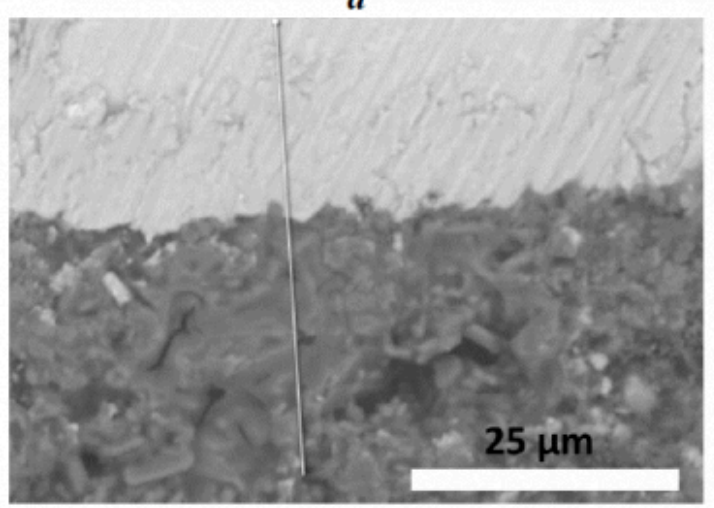

$c$

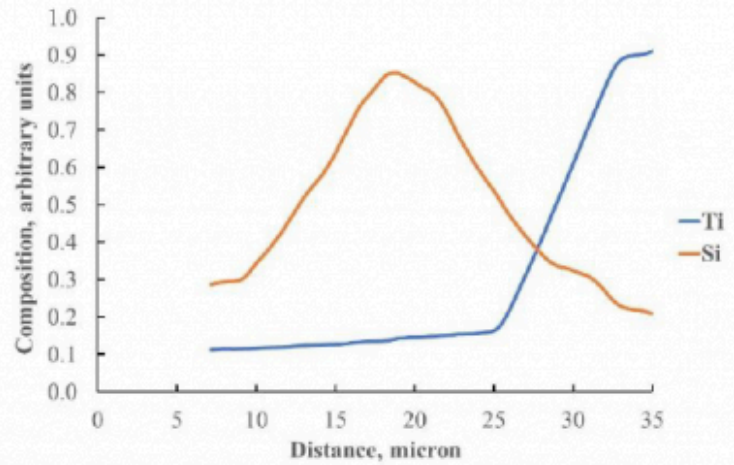

b

Fig. 4. Composition profiles of Ti and Si across the interface metal-ceramic (c); 552 adhesive after standard curing cycle (a) and after $700{ }^{\circ} \mathrm{C}$ curing step (b).

As said before, the performance of 552 adhesive is not influenced by the cure temperature. This result agrees with the results of EPMA analysis, in fact in the case of both standard cure cycle and the $700{ }^{\circ} \mathrm{C}$ one, the composition profiles of Ti and Si indicates interdiffusion.

The adhesion mechanism between titanium and ceramic adhesives is based upon different mechanisms, mainly secondary bonds and the formation of a reaction layer. Since the formation of a reaction layer is based upon interdiffusion, the results reported above indicate that in the case of 503 adhesive, the additional curing step promotes the formation of a reaction layer that increases the adhesion strength between metal and ceramic, while in the case of standard curing cycle the adhesion is realized only by secondary bonds.

The 552 adhesive with a silicate matrix is more reactive towards titanium, probably due the great affinity of $\mathrm{Ti}$ and $\mathrm{Si}$, and the reactive interface is established with the standard cure cycle. The additional step at $700{ }^{\circ} \mathrm{C}$ does not modify the interface. Since the fracture mode of the joint is mixed, improving the interface adhesion improves the global strength of the joint.

\section{Conclusions}

Ceramic adhesives are suitable to realize joints between ceramics and Ti6Al4V, particularly when environmental stability is required. In order to establish a good adhesion between metal and ceramic, the formation of a conversion layer is necessary. To this aim, the phosphate-based adhesive requires an additional curing step at high temperature. On the contrary, the silicate based adhesive is capable to react with titanium already during the standard curing cycle. 


\section{Acknowledgements}

The authors acknowledge the MIUR (Italian Ministry of University and Research) for funding this research through PON AMICO (ARS 01_00758)

\section{Bibliography}

[1] Greenhut VA. Joining of Ceramic-Metal Systems: An Overview. In: BROOK RJ, editor. Concise Encycl. Adv. Ceram. Mater., Oxford: Pergamon; 1991, p. 259 -63. doi:https://doi.org/10.1016/B978-0-08-034720-2.50074-5.

[2] Klomp JT. Joining of Ceramic-Metal Systems: Procedures and Microstructures. In: BROOK RJ, editor. Concise Encycl. Adv. Ceram. Mater., Oxford: Pergamon; 1991, p. 263-71. doi:https://doi.org/10.1016/B978-0-08-034720-2.50075-7.

[3] Song JH, Evans JRG. On the machinability of ceramic compacts. J Eur Ceram Soc 1997;17:1665-73. doi:https://doi.org/ 10.1016/S0955-2219(97)00041-1.

[4] Williams O, Liu C, Webb DP, Firth P. Epoxy adhesive behaviour on ceramic surfaces in commercial optoelectronic assemblies. Int J Adhes Adhes 2010;30:225-35. doi:https://doi.org/10.1016/j.ijadhadh.2010.02.001.

[5] Akselsen OM. Advances in brazing of ceramics. J Mater Sci 1992;27:1989-2000. doi:10.1007/BF01117909.

[6] Wang M, Liu J, Du H, Hou F, Guo A, Zhao Y, et al. Joining of silicon carbide by a heat-resistant phosphate adhesive. RSC Adv 2014;4:31821-8. doi:10.1039/C4RA05005C.

[7] Lahoti M, Tan KH, Yang E-H. A critical review of geopolymer properties for structural fire-resistance applications. Constr Build Mater 2019;221:514-26. doi:https://doi.org/10.1016/j.conbuildmat.2019.06.076.

PDF automatically generated on 2021-05-20 18:23:22

Article url: https://popups.uliege.be/esaform21/index.php?id=4257

published by ULiège Library in Open Access under the terms and conditions of the CC-BY License (https://creativecommons.org/licenses/by/4.0) 